\title{
Penerapan Zachman Framework dalam Merancang Customer Relationship Management pada Bank Perkreditan Rakyat
}

\section{Implementation of Zachman's Framework in Designing Customer Relationship Management at Bank Perkreditan Rakyat}

\author{
I Dewa Ayu Eka Yuliani \\ STMIK Pontianak; Jl. Merdeka No. 372 Pontianak, 0561-735555 \\ Jurusan Sistem Informasi, STMIK Pontianak, Pontianak \\ dewaayu.ekayuliani@gmail.com
}

\begin{abstract}
Abstrak
Penggunaan Zachman Framework sebagai arsitektur dalam merancang customer relationship management bertujuan untuk menggambarkan arsitektur organisasi secara umum dan menguraikannya sebagai sistem informasi perusahaan yang lebih kompleks. Pada penelitian ini Zachman Framework digunakan untuk membangun rancangan arsitektur dari Customer Relationship Management pada BPR Tamara Dana Khatulistiwa. Matriks dari Zachman Framework yang digunakan adalah ukuran $3 x \quad 5$ dimana setiap kolom mempresentasikan data, proses dan jaringan yang menjelaskan pengertian dan berkenaan dengan hal signifikan dari perusahaan, tentang informasi apa yang akan ditangani, sedangkan setiap baris mempresentasikan scope description, model of the business, model of the information sistem, technology model, dan technology definiton. Hasil dari penerapan Zachman Framework untuk merancang CRM adalah peningkatan layanan terhadap nasabah dengan membuat desain sistem, yang dimodelkan dengan menggunakan diagram UML, dan rancangan aplikasi CRM berbasis website yang memiliki fasilitas untuk mengelola data nasabah, tampilan produk perbankan, forum antara nasabah dengan CSO, dan menampilan Frequently Ask Question (FAQ).
\end{abstract}

Kata kunci-Arsitekur Sistem Informasi Perusahaan, Zachman Framework, CRM

\begin{abstract}
The purpose of zachman framework is to comprehensively describe organization architecture and move to more clearly defined complex management information system. This research utilizes zachman framework to create organization architecture design, specifically in customer relationship management area at BPR Tamara Dana Khatulistiwa. 3 columns and 5 rows matrix is used in which every column represents data, process and network, and each row represents scope description, model of the business, model of the information sistem, technology model, dan technology definiton. The result of this study is a web based CRM program design. The program is designed to be able to manage customer data, display financial programs or products discussion forum for customer and customer service and frequently asked questions (FAQ) section. The program is designed using UML diagram and expected to increase customer service level in accordance to business process and zachman framework.
\end{abstract}

Keywords-Enterprise Information System Architecture, Zachman Framework, CRM 


\section{PENDAHULUAN}

Nasabah memiliki peranan penting dan menjadi salah satu faktor kesuksesan di dalam bisnis perbankan, oleh karena itu untuk dapat mempertahankan dan meningkatkan nasabah agar dapat terus bertransaksi dan menggunakan fasilitas yang disediakan bank tersebut, pengelola bank perlu memahami tentang kualitas pelayanan yang baik agar dapat memberikan dan meningkatkan pelayanan yang baik kepada nasabah. Pelayanan yang berkualitas akan memberikan kepuasan kepada nasabah dan menjadi dasar untuk terciptanya loyalitas nasabah. Selain itu, pelayanan yang berkualitas juga akan menciptakan promosi dan rekomendasi nasabah existing kepada orang lain dari mulut ke mulut sehingga bank akan memiliki nasabah yang baru.

Loyalitas nasabah dihadapkan dengan permasalahan pemahaman terhadap kualitas pelayanan, untuk itu dibutuhkan sebuah sistem yang memiliki kemampuan untuk memperoleh nasabah yang lebih banyak dan juga mampu mempertahankan nasabah yang telah ada. Peningkatan kualitas pelayanan kepada nasabah dapat dilakukan dengan menggunakan strategi customer relationship management (CRM). Strategi CRM dapat membangun relasi yang erat antara perusahaan dengan para pelanggannya [1], selain itu CRM mendukung suatu perusahaan untuk menyediakan pelayanan kepada pelanggan secara real time [2]. Strategi CRM dibutuhkan oleh Bank Perkreditan Rakyat (BPR) dalam memberikan pelayanan yang terbaik bagi nasabahnya.

Bank Perkreditan Rakyat (BPR) merupakan salah satu lembaga keuangan yang melayani golongan pengusaha mikro, kecil, dan menengah. Sama seperti bank umum lainnya BPR juga memiliki nasabah yang menempatkan dananya dalam bentuk tabungan atau deposito, dan nasabah yang memerlukan pembiayaan untuk usaha. Berdasarkan data dari Perhimpunan Bank Perkreditan Rakyat Indonesia (Perbarindo), sampai dengan tahun 2017 terdapat 20 (dua puluh) BPR yang beroperasi di Kalimantan Barat dan salah satunya adalah BPR Tamara Dana Khatulistiwa. Banyaknya BPR yang beroperasi di Kalimantan Barat membuat BPR Tamara Dana Khatulistiwa membutuhkan solusi dalam bersaing dengan BPR lain, dan solusi tersebut dapat dilakukan dengan cara meningkatkan kualitas pelayanan terhadap nasabah melalui strategi CRM.

Sistem CRM yang akan menjadi solusi bisnis bagi BPR Tamara Dana Khatulistiwa merupakan sistem yang dapat memudahkan karyawan mengetahui informasi tentang nasabah dengan cepat [3], dimana aktivitas utama dari sistem CRM menitikberatkan pada pembangunan database nasabah yang kuat, dan membuat profil dari setiap nasabah. Penggunaan kerangka kerja (framework) yang baik diperlukan sebagai acuan dalam menerapkan teknologi informasi sebagai salah satu solusi bisnis [2]. Salah satu kerangka kerja yang dapat digunakan adalah Kerangka Zachman (Zachman Framework).

Zachman Framework diperkenalkan oleh John A. Zachman pada tahun 1987 di IBM System Journal dengan tujuan untuk menyediakan sebuah struktur yang mendukung akses integrasi, interpretasi, pengembangan, pengelolaan dan perubahan perangkat arsitektural dari sebuah sistem informasi organisasi [4]. Zachman Framework dapat membantu manajemen dalam melaksanakan dual hal utama yaitu memisahkan komponen-komponen utama sistem informasi yaitu data, proses, dan teknologi agar mudah dalam melakukan perencanaan dan pengembangan di dalam organisasi, kemudian hal yang berikutnya adalah membangun sebuah perencanaan strategis di dalam organisasi dari tingkat konseptual sampai dengan teknis pelaksanaan. Penggunaan Zachman Framework sebagai pendekatan dalam membangun Sistem CRM bertujuan agar model sistem yang akan dibangun lebih kompleks dan menyeluruh, serta sesuai kebutuhan BPR Tamara Dana Khatulistiwa. 


\section{METODE PENELITIAN}

Penelitian ini menggunakan metode penelitian Research and Development (penelitian dan pengembangan). Research and development dapat didefinisikan sebagai suatu proses atau langkah-langkah untuk mengembangkan suatu produk baru atau menyempurnakan produk yang telah ada, yang dapat dipertanggung jawabkan. Produk tersebut tidak harus berbentuk benda atau perangkat keras (hardware), seperti buku, modul, alat bantu pembelajaran di kelas atau di laboratorium, tetapi bisa juga perangkat lunak (software) seperti program komputer [5]. Dalam penelitian ini Research and development dimanfaatkan untuk menghasilkan sebuah arsitekur customer relationship management sebagai upaya untuk meningkatkan pelayanan kepada nasabah BPR Tamara Dana Khatulistiwa.

Tahapan penelitian dimulai dari dari pengumpulan data yang meliputi wawancara, penyebaran kuesioner, dan studi dokumentasi. Wawancara dilakukan dengan Customer Service Officer (CSO), Relationship Officer dan Sales Funding yang mana hasilnya untuk meningkatkan loyalitas nasabah BPR. Penyebaran kuesioner akan dilakukan kepada staf atau karyawan BPR Tamara Dana Khatulistiwa yang langsung berhubungan atau melayani nasabah, seperti Customer Service Officer (CSO), Relationship Officer, dan Sales Funding. Studi Dokumentasi dilakukan guna memperoleh dokumen-dokumen input dan output serta dokumen pendukung penelitian. Dokumen yang digunakan pada penelitian ini seperti brosur-brosur produk BPR, mutu pelayanan bank, teknologi perbankan digunakan, dan data nasabah. Perancangan penelitian menggunakan zachman framework dengan ukuran matriks 3x5 yang merupakan zachman framework yang dipublikasikan pada tahun 1987, dimana tahapan analisis dan perancangan dilakukan dengan menjawab setiap pertanyaan pada tiap kolom matriks dari zachman framework yaitu what, how, dan where, tiap kolom matriks zachman framework ini memiliki baris, yaitu Scope Description (Ballpark View), Model of the Business (Owner's View), Model of the Information System (Designer's View), Technology Model (Builder's View), dan Detailed Description (Out-of-Context View) [6].

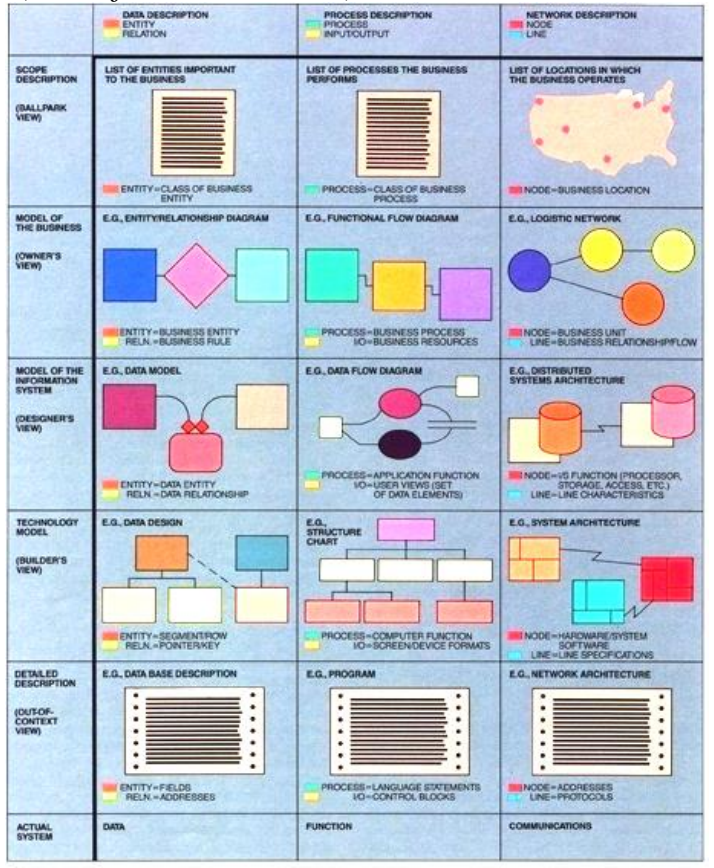

Gambar 1 John Zachman's Information System Architecture (Zachman, 1987:265)

Scope description (ballpark view) merupakan baris yang menjelaskan segala macam objek yang penting untuk bisnis, proses bisnis, dan lokasi bisnis. Model of the business (owner's 
view) merupakan baris yang menjelaskan rancangan dari sistem yang akan dibangun dan bagaimana pemodelan data serta proses yang akan dilakukan untuk membangun sistem berdasarkan analisa yang telah dilakukan pada tahap scope description. Model of the information system (designer's view) merupakan tahapan dimana perancang sistem harus mampu menterjemahkan keinginan yang terdapat pada sudut pandang planner dan owner menjadi suatu bentuk yang lebih teknis sehingga dapat dipahami dan direalisasikan pada sudut pandang builder. Technology model (builder's view) membahas mengenai physical data model yaitu rancangan fisik berbasis data yang akan digunakan dan system design yaitu perancangan sistem perangkat lunak komputer. Detailed description (out-of-context view) membahas mengenai peran dan rujukan bagi pihak yang bertanggung jawab untuk melakukan pembangunan sistem informasi.

\section{HASIL DAN PEMBAHASAN}

Tahapan analisa dan perancangan CRM pada BPR Tamara Dana Khatulistiwa Pontianak menggunakan Zachman Framework. Berdasarkan pengumpulan data yang telah dilakukan maka akan dilakukan proses pemetaan masalah ke dalam kerangka Zachman untuk menghasilkan rancangan CRM yang dibutuhkan, kemudian akan disusun dalam kerangka matrik Zachman dengan ukuran 3 x 5 (gambar 1). Baris pertama menjelaskan mengenai segala macam objek yang penting untuk bisnis, proses bisnis, dan lokasi bisnis. Baris pertama pada zachman framework ini yaitu scope description (ballpark's view) disebut dengan arsitektur kontekstual. Arsitektur ini didefinisikan model bisnis fungsional secara global dan berbagai requirement eksternal organisasi. Baris kedua yaitu model of the business (owner's view) menjelaskan rancangan dari sistem yang akan dibangun dan bagaimana pemodelan data serta proses yang dilakukan untuk membangun sistem berdasarkan analisa yang telah dilakukan pada baris scope description. Jika baris kedua menggambarkan keadaan saat ini, maka pada baris ketiga menggambarkan perancangan dari sistem yang akan dibangun. Pada baris ketiga yaitu model of the information system (designer's view), designer sistem harus mampu menerjemahkan keinginan yang terdapat pada sudut pandang planner dan owner menjadi suatu bentuk yang lebih teknis sehingga dapat dipahami dan direalisasikan pada sudut pandang builder. Model dari sistem informasi akan menggambarkan logical data model, application architecture, dan distributed system architecture dari CRM. Baris keempat yaitu technology model membahas mengenai physical data model yaitu rancangan fisik basis data yang akan digunakan dan system design yaitu perancangan sistem perangkat lunak komputer. Baris kelima yaitu detailed description membahas mengenai peran dan rujukan bagi pihak yang bertanggung jawab untuk melakukan pembangunan sistem informasi. Detailed description menjelaskan tentang data definition, program, dan network architecture yang akan digunakan pada CRM.

Scope description mendefenisikan mengenai sasaran dan lingkup bisnis. Baris pertama pada zachman framework ini sering disebut dengan arsitektur kontekstual. Pada arsitektur ini didefinisikan model bisnis fungsional secara global dan berbagai requirement eksternal organisasi. Zachman framework mendefinisikan kolom data sebagai list of things important to business, dimana kolom ini berisi tentang objek paling signifikan yang ditangani oleh perusahaan. Data yang dibutuhkan di dalam merancang CRM pada BPR Tamara Dana Khatulistiwa meliputi data nasabah, data produk, dan data standar operasional pelayanan dari BPR Tamara Dana Khatulistiwa. Deskripsi proses yang terdapat pada kolom kedua baris pertama adalah list of process the business performs berfungsi untuk mendefenisikan daftar proses fungsi-fungsi yang melakukan perubahan proses input menjadi output. Adapun proses yang dilakukan untuk aktivitas CRM di BPR Tamara Dana Khatulistiwa antara lain adalah proses mengindetifikasi target nasabah dapat dilakukan dengan mengkalsifikasikan nasabah berdasarkan usaha dan besar pendapatannya, input yang dibutuhkan tentunya adalah data profile nasabah yang dimiliki oleh BPR Tamara Dana Khatulistiwa. Proses berikutnya adalah proses mempertahankan nasabah, dimana dapat menjaga hubungan baik dengan nasabah tentunya 
harus didukung dengan memberikan pelayanan terbaik yang menguntungkan nasabah. Layanan terbaik tersebut tentunya dapat dipelajarai dari standar pelayanan nasabah dari BPR Tamara Dana Khatulistiwa sehingga pelayanan yang diberikan kepada nasabah dapat maksimal dan sesuai dengan standar yang telah ditetapkan. Proses terakhir adalah menyediakan fasilitas informasi untuk karyawan yang melayani keinginan dan kebutuhan nasabah, untuk itu harus ada fasilitas informasi yang dibutuhkan karyawan mengenai profil lengkap dari nasabah, dan tidak lagi diberikan melalui telepon atau memo, namun dapat ditampilkan dari database yang akan dirancang untuk BPR Tamara Dana Khatulistiwa. Kolom berikutnya pada scope description adalah jaringan yang berkenaan dengan distribusi geografis dari kegiatan perusahaan dan bagaimana setiap elemen berkomunikasi dengan yang lain untuk mendukung penyediaan dan penyimpanan data. Kantor cabang BPR Tamara Dana Khatulistiwa terletak di Jl. Gajah Mada No. 26-27 Pontianak Kalimantan Barat, dan saat ini belum memiliki kantor cabang lainnya, sehingga untuk CRM yang akan dirancang hanya diprioritaskan pada entitas berada dalam satu bangunan yang sama. Masing-masing entitas yaitu Customer Service Officer, Relationship Officer, dan Sales Funding memiliki 1 (satu) unit Personal Computer (PC) yang dipergunakan untuk mendukung pekerjaan mereka, namun PC yang digunakan tidak terkoneksi dengan jaringan internet, tapi terkoneksi dengan VPN (Virtual Private Network) pada BPR Tamara Dana Khatulistiwa, sehingga masing-masing PC yang digunakan oleh entitas tentunya akan dapat terkoneksi dengan PC entitas lainnya.

Model of the business akan menjelaskan model bisnis yang dilihat dari sudut pandang pemilik (owner), model ini sering disebut dengan arsitektur konseptual. Model ini menjelaskan rancangan dari sistem yang akan dibangun dan bagaimana pemodelan data serta proses yang dilakukan untuk membangun sistem berdasarkan analisa yang telah dilakukan pada baris scope description. Pada baris ini kolom data atau disebut semantic model menggambarkan tentang entitas data yang terdapat pada arsitektur CRM. Entity-Relationship adalah salah satu metode pemodelan basis data yang digunakan untuk menghasilkan skema konseptual untuk jenis atau model data semantik sistem. Model data tersebut dapat digambarkan dengan menggunakan E-R Diagram. E-R diagram yang digambarkan memiliki entitas yaitu, nasabah, produk, nasabah, karyawan, masalah, dan solusi. Dimana hubungan antara entitas tersebut adalah satu produk yang dapat dipilih oleh banyak nasabah, dan satu orang nasabah dapat memiliki lebih dari satu produk yang ada di BPR Tamara Dana Khatulistiwa, kemudian seorang nasabah dapat memiliki banyak masalah, dan beberapa masalah yang sama dapat dimiliki oleh satu orang atau lebih nasabah, banyak masalah dapat dilaporkan ke satu orang karyawan (CSO/RO/SF) dan satu orang karyawan (CSO/RO/SF) dapat menangani banyak permasalahan, seorang karyawan (CSO/RO/SF) dapat memberikan sebuah solusi atau tidak ada solusi yang dapat diberikan, dan satu solusi yang sama atau tidak ada solusi dapat diberikan oleh satu orang atau banyak karyawan $(\mathrm{CSO} / \mathrm{RO} / \mathrm{SF})$.

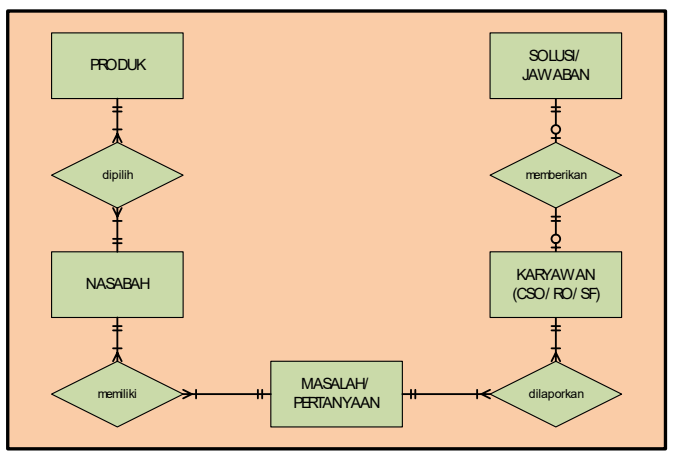

Gambar 2 Diagram E-R Entitas Data

The business process model meliputi hubungan area fungsi dan entitas data adalah dalam hal pembuatan, pengolahan, dan penggunaan data untuk keperluan pemenuhan fungsi 
bisnis. Kolom ini berisikan berbagai macam kebijakan (policy), prosedur dan standar yang terkait dengan model business rule. Aturan bisnis dibuat tergantung dari kompleksitas transaksi, aturan-aturan bisnis harus dibuat untuk memastikan bahwa transaksi dengan nasabah dilakukan dengan efisien. Business logistics system berfungsi untuk menggambarkan posisi atau letak entitas-entitas di dalam BPR Tamara Dana Khatulistiwa yang terkait di dalam pelayanan nasabah. Lokasi dan hubungannya digambarkan dalam bentuk jaringan sederhana berupa node/simpul (unit bisnis) dan line/garis (relasi) yang menghubungkan node tersebut (Gambar 3).

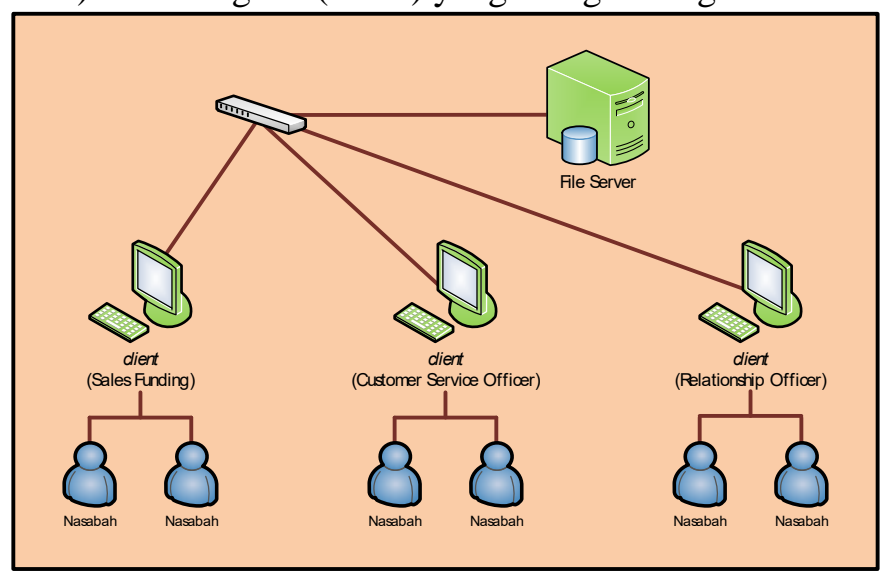

Gambar 3 Topologi Jaringan Entitas CRM

Information system model digunakan untuk menggambarkan keaadaan sistem dan informasi yang dapat akan dibangun dari sistem saat ini yang dijelaskan pada baris model of the business. Model dari sistem informasi akan menggambarkan logical data model, application architecture, dan distributed system architecture dari CRM untuk BPR Tamara Dana Khatulistiwa. Logical data model digunakan untuk menggambarkan atribut beserta kunci yang berkaitan dengan catatan informasi dari perusahaan baik yang terotomatisasi maupun yang tidak terotomatisasi. Untuk menggambarkan atribut tersebut dapat menggunakan Entity Relationship Diagram (E-R Diagram) yang dapat menunjukkan relasi dari setiap entitas-entitas yang terkait pada pelayanan nasabah di BPR Tamara Dana Khatulistiwa (Gambar 4).

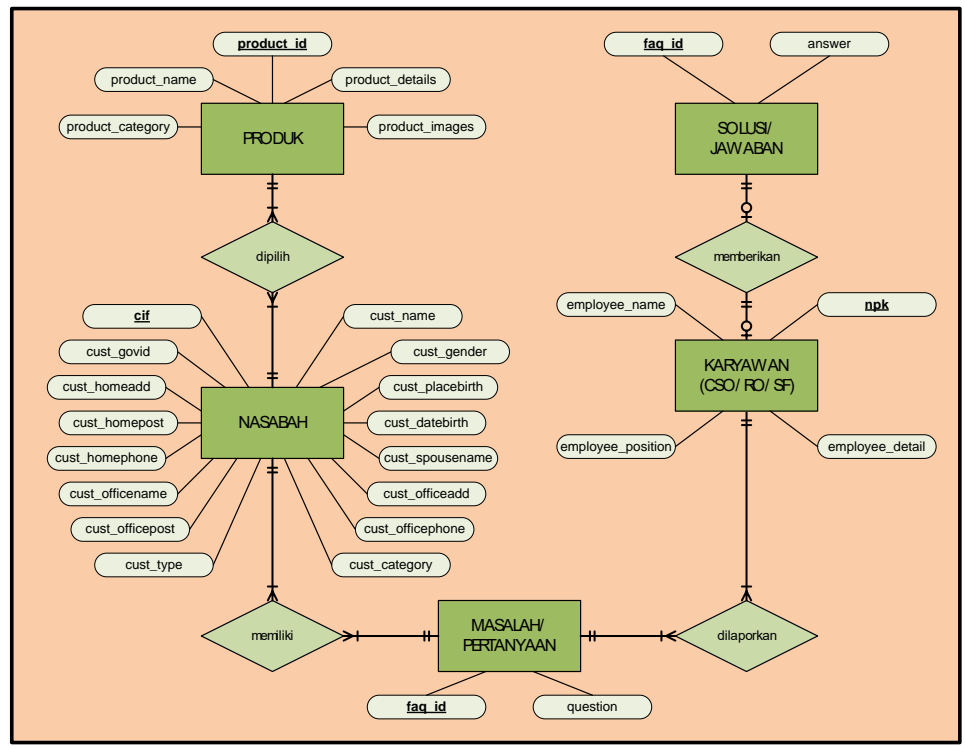

Gambar 4 Diagram E-R Entitas Data, Atribut, dan Kunci 
Application architecture digunakan untuk menggambarkan proses kerja dari sistem yang diusulkan untuk rancangan CRM. Proses berisikan representasi logik dari sistem informasi dan hubungannya yang digambarkan pada arsiktektur CRM. Dalam arsitektur CRM terlihat bagaimana unsur-unsur penyusun CRM tersebut saling berinteraksi. Unified Modelling Language (UML) digunakan untuk memodelkan arsitektur aplikasi yang akan dirancang untuk arsitektur CRM. UML mendefinisikan dalam beberapa diagram-diagram, diantaranya ada 4 diagram yang akan dipakai dalam perancangan yaitu use case diagram, class diagram, activity diagram dan sequence diagram. Use case diagram menggambarkan fungsionalitas yang diharapkan dari sebuah sistem. Yang ditekankan adalah "apa" yang diperbuat sistem, dan bukan "bagaimana", secara lebih detail, masing-masing use case yang terdapat pada diagram use case, dijabarkan dalam skenario use case yang akan menjelaskan secara detail interaksi yang ada di dalamnya. Untuk produk yang ditampilkan pada rancangan halaman utama CRM user juga diharuskan untuk login sebelumnya. Setelah masuk ke halaman admin maka user dapat menambah, merubah, atau menghapus produk yang ada. Rancangan arsitektur CRM juga menampilkan profil perusahaan dari BPR Tamara Dana Khatulistiwa, untuk melihat profil tersebut user tidak diharuskan login tapi untuk dapat menambah, merubah, atau menghapus data profil perusahaan user harus login terlebih dahalu. Data nasabah BPR Tamara Dana Khatulistiwa tidak dapat dipublikasikan secara umum, hanya karyawan yang memiliki user account pada aplikasi CRM yang dapat melihatnya (Gambar 5). Distributed systems architecture yang berisi representasi logik mengenai arsitektur sistem terdistribusi untuk masing-masing lokasi dari sistem yang dirancang. Kolom ini berisikan representasi logik mengenai arsitektur sistem terdistribusi untuk masing-masing lokasi. CRM pada BPR Tamara Dana Khatulistiwa dirancang dengan menggunakan database terdistribusi dimana nantinya nasabah dapat mengakses CRM dimanapun mereka berada.

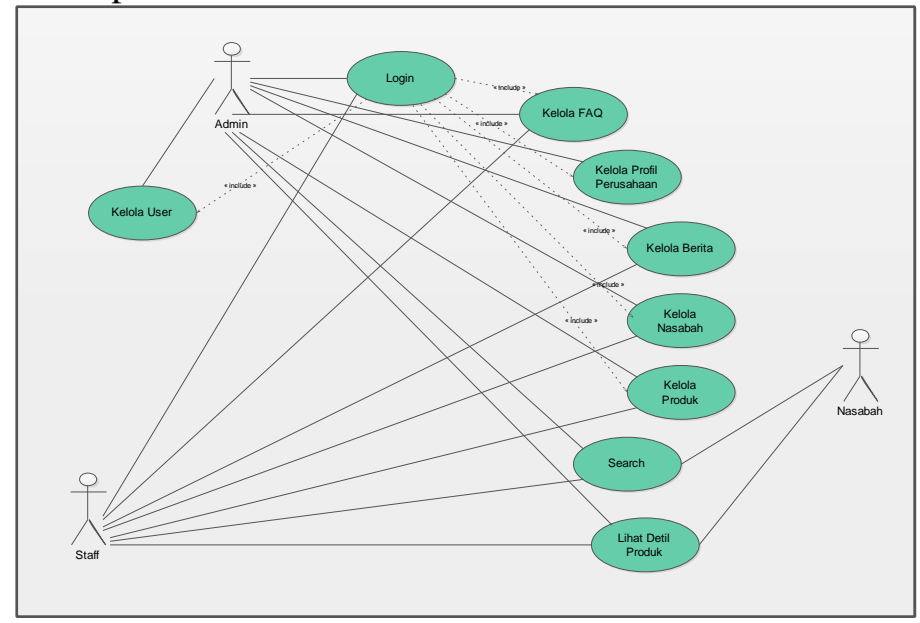

Gambar 5 Diagram Use Case

Aplikasi CRM dibagi menjadi dua bagian, ada halaman yang dapat diakses secara bebas oleh semua user, dan ada halaman yang bisa diakses oleh admin dan karyawan yang ditugaskan untuk melayani nasabah BPR Tamara Dana Khatulistiwa. Untuk mengakses halaman admin user diharuskan login terlebih dahulu, tanpa login user tidak akan bisa melihat beberapa content khusus di dalam sistem CRM. Setelah masuk ke admin page ada beberapa content yang dapat dilihat, dirubah, dan dihapus oleh user tergantung dari hak akses yang diberikan kepada user tersebut. Content yang pertama adalah mengelola frequently ask question (FAQ), dimana user dapat menambah daftar pertanyaan yang paling sering ditanyakan oleh nasabah, sehingga jika nasabah bertanya kembali, CSO/RO/SF tidak perlu mencari informasi atas jawaban dari pertanyaan nasabah. Content berikutnya adalah pengelolaan profil perusahaan, pengelolaan berita yang hanya dapat dilakukan oleh admin atau staf yang memiliki hak akses pada sistem 
CRM. Pengelolaan nasabah dan pengelolaan produk perbankan dapat dilakukan oleh admin atau staf yang ditugaskan untuk melayani nasabah BPR Tamara Dana Khatulistiwa. Terpat juga content untuk melihat daftar ulang tahun nasabah BPR Tamara Dana Khatulistiwa, proses ini hanya dapat dilakukan oleh admin dan staff BPR Tamara Dana Khatulistiwa. Selain itu juga terdapat content untuk mengelola data Standard Operational Procedure (SOP) sebagai pedoman bagi pelayanan nasabah dan fasilitas bagi nasabah untuk mengirim pesan langsung ke $\mathrm{CS} / \mathrm{RO} / \mathrm{SF}$ yang menangani mereka.

Technology model membahas mengenai sistem manajemen data dan perangkat lunak komputer. Selain itu baris ini juga menjelaskan rancangan dari jaringan komputer dan komunikasi yang dirancang. Kolom data yaitu physical data model membahas mengenai desain fisik basis data yang akan digunakan pada arsitektur CRM. Untuk merancang arsitektur CRM pada BPR Tamara Dana Khatulistiwa maka dibuatlah sebuah perancangan database yang meliputi struktur database dari CRM yang akan dirancang dan Entity Relationship Diagram yang akan menggambarkan hubungan antar tabel pada database CRM BPR Tamara Dana Khatulistiwa (Gambar 6).

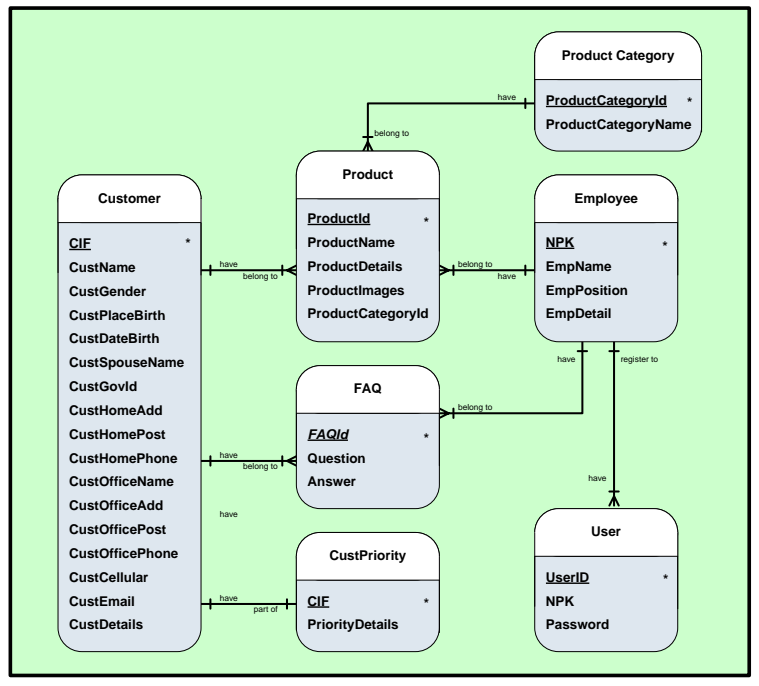

Gambar 6 Diagram E-R Databse CRM

CRM yang akan dirancang merupakan suatu sistem yang memanfaatkan teknologi berbasis komputer, perancangan sistem ini dibuat untuk mengatasi masalah yang telah diidentifikasi sehingga dapat membantu BPR Tamara Dana Khatulistiwa dalam meningkatkan pelayanan kepada nasabahnya. Adapun perancangan antarmuka yang akan dibangun dengan menggunakan Web Based Application. Perancangan halaman utama website CRM ini terdiri dari halaman utama, halaman profil perusahaan, halaman data nasabah, halaman FAQ, dan halaman berita. Halaman utama akan muncul pada saat user mengunjungi website CRM, halaman ini berisi tentang berita terupdate baik mengenai produk dan program terbaru yang sedang diluncurkan oleh BPR Tamara Dana Khatulistiwa maupun tentang kegiatan yang sedang atau telah dilakukan oleh BPR Tamara Dana Khatulistiwa di masyarakat (Gambar 7). 


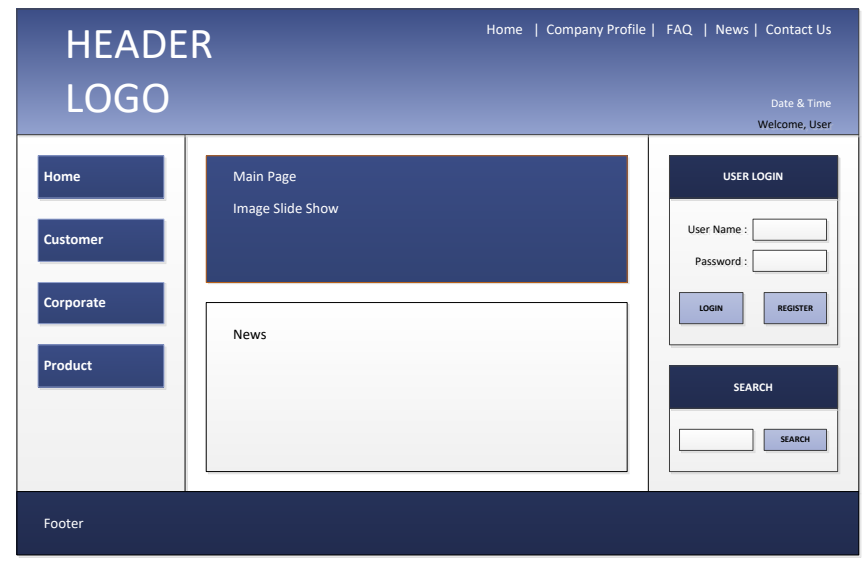

Gambar 7 Rancangan Halaman Utama Sistem CRM

Technology architecture menggambarkan deskripsi dari perangkat keras, perangkat lunak, dan topologi jaringan yang dibutuhkan untuk dapat mengimplementasikan sistem yang telah dirancang pada sistem CRM. Untuk membangun sistem CRM pada BPR Tamara Dana Khatulistiwa, arsitektur topologi jaringan yang digunakan adalah topologi star (bintang). Hal ini dikarenakan server atau akses kontrol sebagai terminal pusat bertindak sebagai pengatur dan juga pengendali komunikasi antara admin pengawas, customer service, relationship officer, dan sales funding didalam sistem aplikasi CRM (Gambar 8). Kelebihan dalam menggunakan topologi star bagi sistem aplikasi CRM antara lain tingkat keamanan cukup tinggi, penambahan atau pengurangan station dapat dilakukan dengan mudah, kerusakan pada satu saluran tidak mempengaruhi saluran lain, tahan terhadap arus lalu lintas jaringan yang sibuk, mudah dalam mendeteksi kerusakan dan kesalahan pengelolaan dalam jaringan. Namun terdapat pula kelemahan dari topologi yang digunakan antara lain, pemakaian kabel jaringan menjadi banyak sehingga biaya pengadaan jaringan menjadi lebih mahal, hal ini dapat diatasi dengan penataan ruang kerja yang maksimal sehingga server memiliki jarak yang tidak jauh dengan user yang mengakses sistem tersebut. Kelemahan berikutnya adalah peran switch merupakan elemen kritis dan sangat sensitive perlu dijaga jangan sampai bermasalah karena jika mengalami gangguan atau kerusakan maka rangkaian jaringan akan berhenti. Hal ini didapat diminimalisasi dengan memaintenance dan mengontrol switch secara rutin minimal sebulan sekali sehingga jika terjadi indikasi gangguan atau kerusakan, bisa dapat segera diperbaiki. Selain itu, selalu menyediakan switch cadangan jika tiba-tiba switch mengalami kerusakan dan gangguan. Pengimplementasikan sistem CRM juga membutuhkan spesifikasi minimal dari perangkat keras dan perangkat lunak untuk komputer client dan komputer server yang menunjang sistem CRM tersebut. 


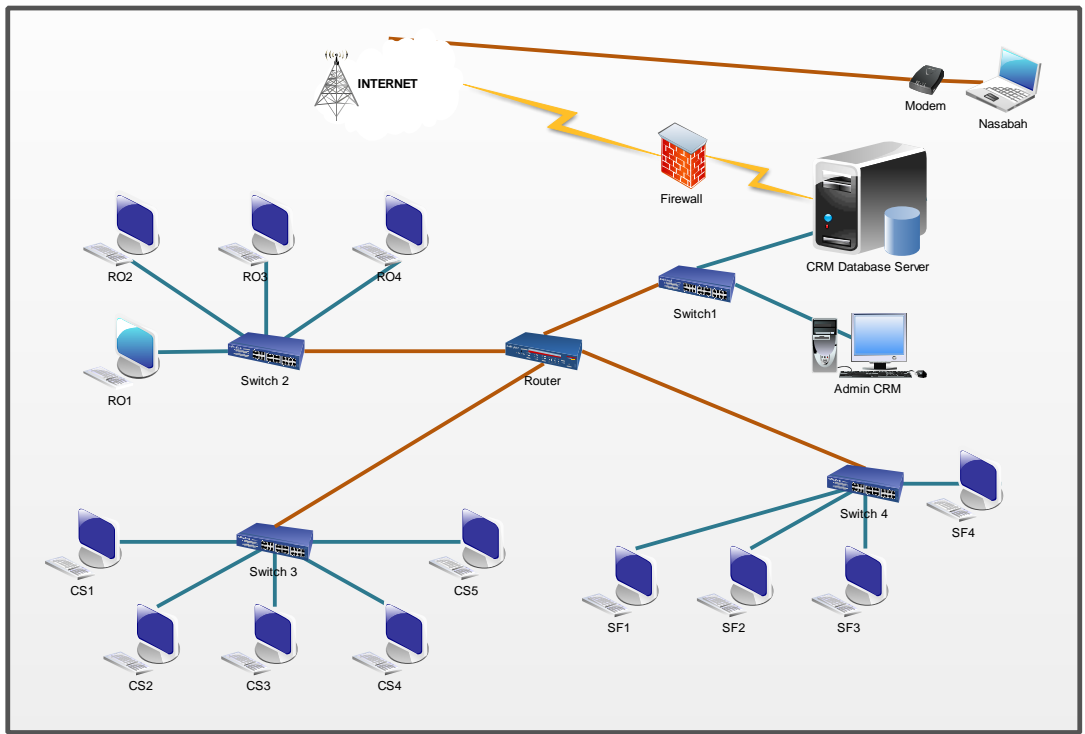

Gambar 8 Topologi Jaringan Sistem CRM

Baris yang terakhir di dalam matriks Zachman Framework adalah technology definition, baris ini membahas mengenai peran dan rujukan bagi pihak yang bertanggung jawab untuk melakukan pembangunan sistem informasi. Baris ini menjelaskan tentang bagaimana data disimpan ke dalam komputer dengan teknologi tertentu dari manajemen data, perspektif dari bahasa pemrograman tertentu, dan protokol dan komponen tertentu dari jaringan komunikasi. Deskripsi data untuk baris kelima adalah data definiton yang merupakan defenisi dari physical data model yang telah dijabarkan pada baris techonogy model. Data definition memuat semua data definition language yang berfungsi untuk mendefinisikan suatu tabel, index, dan view yang dibutuhkan dalam implementasi CRM (Gambar 9).

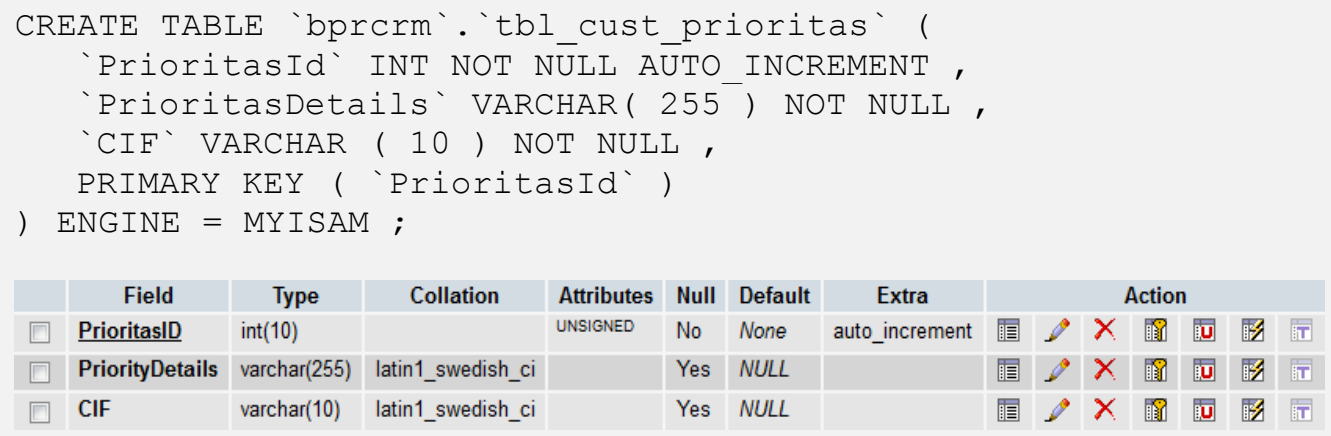

Gambar 9 Data Defenition Sistem CRM

Kolom berikut nya adalah process description atau programs dimana kolom ini menjelaskan mengenai perspektif dari bahasa pemrograman tertentu, CRM yang dikembangkan adalah sebuah sistem berbasis web yang dirancang dengan menggunakan bahasa pemrograman PHP. PHP adalah bahasa umum yang digunakan untuk membuat sebuah pengembangan web. PHP umumnya berjalan pada web server, yaitu menggunakan kode PHP sebagai inputan, dan menciptakan sebuah halaman web sebagai hasil output. PHP dapat dijalankan di sebagian besar web server, beberapa sistem operasi dan digunakan dengan beberapa sistem manajemen database. PHP tersedia secara gratis, dan PHP menyediakan kode yang lengkap yang dapat 
digunakan oleh pengguna untuk membangun, mengatur dan memperluas sesuai yang diinginkan. Sistem yang dirancang direncanakan akan digunakan oleh staf BPR Tamara Dana Khatulistiwa yang khusus menangani nasabah seperti Customer Service Officer, Relationship Officer, dan Sales Funding. Namun dikarenakan sistem tersebut berbasis web maka sistem dapat dihosting pada sebuah server sehingga dapat digunakan pula untuk nasabah BPR Tamara Dana Khatulistiwa. Kolom ketiga pada matriks ini adalah network architecture, di dalam kolom ini membutuhkan sebuah konfigurasi perangkat jaringan yang dapat menunjang sistem aplikasi tersebut. Konfigurasi perangkat jaringan tersebut harus dijabarkan lebih spesifik dan memuat konfigurasi minimal dari jaringan yang dianjurkan dapat berupa spesifikasi perangkat keras untuk komputer server dan untuk komputer client sehingga diperoleh sebuah jaringan yang memadai untuk mengoptimalkan penggunaan aplikasi CRM tersebut.

\section{KESIMPULAN}

Perancangan arsitektur customer relationships management (CRM) untuk Bank Perkreditan Rakyat (BPR) menerapkan kerangka kerja Zachman (Zachman Framework) sebagai pendukung integrasi, pengembangan, dan pengelolaan arsitektur dari sebuah sistem. Zachman Framework menggunakan ukuran matriks 3 x 5, dimana matriks tersebut menguraikan secara detail kolom data, process, dan network pada masing-masing baris yaitu scope description (ballpark view), model of the business (owner's view), model of the information system (designer's view), technology model (builder's view), dan detailed description (out-of-context view). Perancangan sistem CRM untuk Bank Perkreditan Rakyat meliputi perancangan informasi dari perusahaan, tampilan produk perbankan, forum antara nasabah dengan CSO, dan menampilan Frequently Ask Question (FAQ) yang sering menjadi permasalahan yang ditanyakan oleh nasabah. Selain itu juga mencakup kelengkapan data pribadi nasabah yang meliputi tanggal lahir, hobi, dan kebiasaan dari nasabah yang harus dipahami benar oleh CSO ataupun Relationship Officer untuk menunjang pelayanan ekslusif terhadap nasabah yang telah memberi kontribusi besar pada BPR Tamara Dana Khatulistiwa.

\section{SARAN}

Pemeliharaan dan pengembangan sistem harus terus dilakukan sehingga sistem CRM dapat berjalan dengan baik dan dapat memenuhi kebutuhan informasi yang diperlukan perusahaan dimasa sekarang dan yang akan datang. Pengembangan customer relationship management diharapkan sampai pada totalisasi aplikasi perbankan seperti pengiriman informasi kurs mata uang, maupun saldo nasabah. Pengembangan CRM juga dilakukan pada Back Officer agar dapat memberikan perhatian utama terhadap jalannya transaksi nasabah, juga pada pemanfaatan database dalam data mining informasi untuk pemasaran Bank Internasional Indonesia cabang Pontianak. Penambahan keamanan jaringan pada keseluruhan database sehingga database tidak dapat diakses oleh pihak-pihak yang tidak bertanggung jawab dan tidak berkepentingan.

\section{DAFTAR PUSTAKA}

[1] Deriani, Ni Wayan, 2016, Analisa Perancangan Model Customer Relationship Management pada STMIK STIKOM Bali, Jurnal VOI STMIK Tasikmalaya, Vol. 5, No. 2, pp. 43-55

[2] Zulfata, Ghaniyu., dkk., 2017, Pengembangan Electronic Customer Relationship Management (E-CRM) Pada Toko Sepatu Aneka Sport Malang Dengan Metode 
Penerapan Zachman Framework Dalam Merancang ...

Kerangka Kerja Dynamic CRM, Jurnal Pengembangan Teknologi Informasi dan Ilmu Komputer, Vol. 2, No. 4, pp. 1419-1427

[3] Kosasi, Sandy, 2015, Perancangan Sistem Electronic Customer Relationship Management Untuk Mempertahankan Loyalitas Pelanggan, Jurnal Sistem Informasi dan Teknologi Informasi (JUSITI), Vol. 4, No. 2, pp. 92-102

[4] Rosalina, Vidila, 2015, Penerapan Zachman Framework dalam Merancang Infrastruktur Jaringan Komputer Customer Relationship Management (CRM) pada Universitas, Jurnal PORSISKO, Vol. 2, No. 2, pp. 74-77

[5] Syaodih, Nana., 2005, Metode Penelitian Pendidikan, Rosdakarya, Bandung.

[6] Zachman, John A., 2003, The Zachman Framework For Enterprise Architecture : Prime For Enterprise Engineering and Manufacturing, (c) 2003 John A. Zachman, Zachman International. 